International Journal of Engineering \& Technology, $7(4.38)(2018) 7-10$
International Journal of Engineering \& Technology
SPC
Website: www.sciencepubco.com/index.php/IJET
Research paper

\title{
Design of PSO Based Cascaded Multilevel Inverter with Unequal DC Sources
}

\author{
${ }^{1}$ Rupali Mohanty, ${ }^{2}$ Debashis Chatterjee, ${ }^{3}$ Gopinath Sengupta \\ ${ }^{1,3}$ Gandhi institute for Technology,Bhubaneswar,Odisha \\ ${ }^{2}$ Jadavpur University, Kolkata, West Bengal \\ ${ }^{1,3}$ Electrical and Electronics Engineering Department \\ ${ }^{2}$ Electrical Engineering Department \\ *Corresponding author E-mail: rupali@gift.edu.in
}

\begin{abstract}
This paper focusing on, the total harmonics distortion (THD) of the output voltage is minimized by the help of a cascade multilevel inverter with non-equal DC sources using particle swarm optimization (PSO) algorithm. The nonlinear transcendental equation that describing the harmonic elimination problem is solved by using many methods existing in literature. In the proposed technique, unequal DC sources are taken for the multilevel inverter, which is practical when different renewable sources are used. The desired switching angles are found out by implementing PSO algorithm which results the minimum THD. Experimental details along with simulation results of 11-level inverter are shown to validate the theory.
\end{abstract}

Keywords: Cascade multilevel inverter, PSO, Total harmonics distortion.

\section{Introduction}

In recent trends the researchers are focusing on solving the energy crises by renewable energy sources.The energy that we get from these sources are in form of DC, so to commercialize or to synchronize it with grid inverter is required for converting this energy in to AC.But the output voltage of this inverter having high harmonics content.To eliminate this harmonics and for minimizing the THD lots of techniques are used.Filter circuits are designed to eliminate the harmonics. The main objective of this experiment is to design a cascade multilevel inverter with unequal DC sources which can minimize the THD to a greater extend without using the filter circuits.An SPWM technique is suggested in [1] where the third harmonics is eliminated in single phase inverter and the rest lower level harmonics are minimized by using the filter circuit.for controlling the output voltage and eliminating the harmonics various PWM techniques are suggested in [2] and [3]. Choosing of suitable switching angels for multilevel inverter to suppress some specific order harmonics ,SHE or PWM techniques with different programming is implemented in[4].The most convenient topology is based on cascade connection of $n$ number of single phase inverter to generate a $(2 n+1)$ level of inverter.Instead of using similar value of DC sources ,unequal DC source are considered so that proper utilization of these sources can be achieved.The SHE techniques is implemented in [6],[7] .using equal voltage sources 6 switching angles found out and using non equal DC sources 3 switching angles found out to eliminate harmonics from multilevel inverter in[6],[7].In [8],[9] the THD was minimized by different algebraic calculation to get the firing angle with analytical proof.But this method is only applicable for three phase case. In [10] a comparative analysis of THD optimization was done in cascade multilevel inverter by using Genetic algorithm and PSO algorithm. But this is only applied to equal DC sources of multilevel inverter. In this paper THD is minimized by using a 11 level inverter with non-equal DC sources. Using PSO algorithm the suitable firing angle is found out for the inverters and to verify the analytical proof hardware model and simulation is done. The FFT analysis is done with different modulation index.

\section{Cascade Multilevel Inverter}

Among all topologies one of the simple and well known topology of multilevel inverter is cascade H-bridge multilevel inverter. It can be used in single phase as well three phase energy conversion. In this case ' $n$ ' numbers of single H-bridge inverter are connected in cascade and provide staircase output voltage which is closer to fundamental AC output. In case of single H-bridge inverter with a square output voltage contains around 40-45\% THD. Where as by using different optimization techniques in cascade multilevel inverter the THD is minimized to a greater extend. The level of output from a multilevel inverter can be determined by the number of separate DC sources used .For example if ' $n$ ' numbers of DC sources are used then the output voltage level will be $(2 n+1)$. Practically it is somehow difficult to use similar magnitude of DC sources of different levels. This may caused by the different charging and discharging time intervals of the DC side source voltage.But if we use the different magnitude of DC source voltage then proper utilization of battery is there as each of the single inverter in this cascade connection is triggered on in different firing angles. Each inverter level is generating three different voltage output i.e $+\mathrm{V}_{\mathrm{DC}}, 0,-\mathrm{V}_{\mathrm{DC}}$. This voltage can be obtained by connecting the DC input to output side by using four switches $\mathrm{S}_{1,1}, \mathrm{~S}_{1,2}, \mathrm{~S}_{1,3}, \mathrm{~S}_{1,4}$. The AC output voltage of the multilevel inverter is the summation of each output inverter connected in series. The switches of all H-bridge inverter are only triggered on at the fundamental frequency.

Figure (1) shows the circuit diagram of cascade multilevel inverter with unequal DC sources $V_{1}, V_{2} \ldots . . V_{k}$ and the output voltage is 
$\mathrm{V}_{0}=\mathrm{V}_{01}+\mathrm{V}_{02}+\ldots+\mathrm{V}_{0 \mathrm{k}}$. The switching angles $\alpha 1, \alpha 2, \alpha 3 \ldots \ldots \alpha \mathrm{k}$ of the multilevel inverter results a sinusoidal voltage waveform with a minimum THD. Figure (2) shows The staircase output voltage wave form of a 11 level inverter is shown in Figure (2). The proper value of switching angles is found out by using different heuristic methods [11], In this paper PSO algorithm is used to get the desire value of firing angles for minimizing the THD.

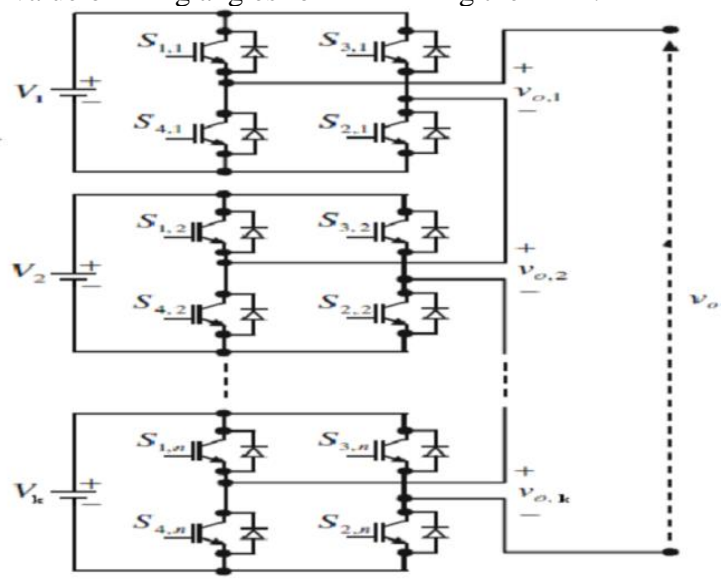

Fig.1: circuit diagram of multilevel inverter

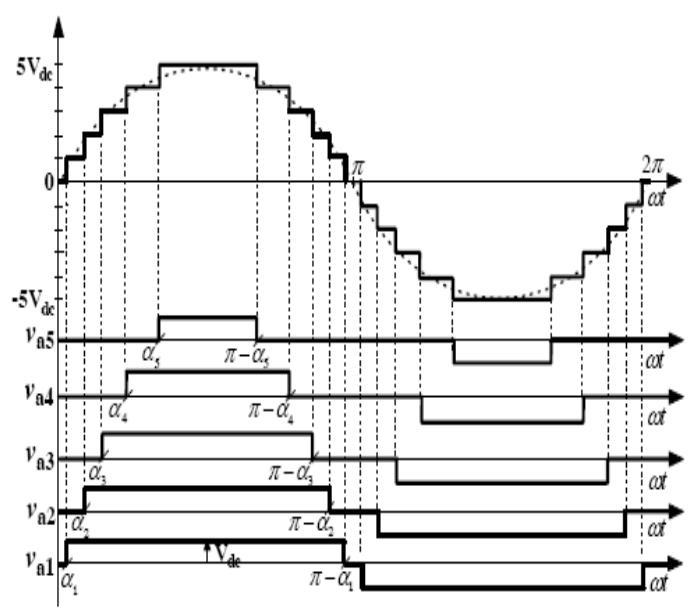

Fig.2: Output voltage waveform of an 11 level inverter, with unequal DC sources

\section{Problem Formulation}

By implementing Fourier series analysis the expression of output voltage waveform of cascade multilevel inverter with unequal DC sources is

$$
\begin{aligned}
& V(\omega t)=\sum_{n=1,3,5}^{\infty} \frac{4 V_{d c}}{n \pi}\left(a_{1} \cos \left(n \alpha_{1}\right)+a_{2} \cos \left(n \alpha_{2}\right)+a_{3} \cos \left(n \alpha_{3}\right)\right. \\
& \left.a_{s} \cos \left(n \alpha_{s}\right)\right) \sin (\omega t)
\end{aligned}
$$

Where $a_{i} \mathrm{~V}_{\mathrm{dc}}$ is the $\mathrm{i}_{\mathrm{th}} \mathrm{DC}$ voltage and $\mathrm{V}_{\mathrm{dc}}$ is the nominal DC voltage. $\alpha_{1}, \alpha_{2} \ldots \ldots \alpha_{\mathrm{s}}$ are the firing angles and these angles must satisfy the below condition.

$0<\alpha_{1}<\alpha_{2}<\ldots \ldots \ldots<\alpha_{s}<\pi / 2$

From the output voltage of inverter the number of harmonics which has to be eliminated can be calculated by using the formula "S-1",where $\mathrm{S}$ is the total number of voltage sources used in the multilevel inverter. For example from a 5 level inverter $5^{\text {th }}$ harmonic can be eliminated as 2 voltage sources are used here. This concept is applicable for three phase power supply as triplet harmonics are eliminated automatically. The equations are

$\left|\begin{array}{c}a_{1} \cos (\alpha 1)+a_{2} \cos (\alpha 2)=\left(\frac{\pi}{2}\right) M \\ a_{1} \cos (5 \alpha 1)+a_{2} \cos (5 \alpha 2)=0\end{array}\right|$

In the above equation $\mathrm{M}$ is the modulation index and is expressed as $\mathrm{M}=\mathrm{V}_{1} / \mathrm{SV}_{\mathrm{dc}}$. $\mathrm{V}_{1}$ is the fundamental voltage of the output waveform. In this paper as 11 level inverter is considered in single phase supply,5 different DC sources are used to get the desired output . Here $S=5$ so $5-1=4$ numbers of harmonics are eliminated here that is $3^{\text {rd }}, 5^{\text {th }}, 7^{\text {th }}, 11^{\text {th }}$ order harmonics. The equations which are to be satisfied:

$\left[\begin{array}{r}a_{1} \cos (3 \alpha 1)+a_{2} \cos (3 \alpha 2)+a_{3} \cos (3 \alpha 3)+a_{4} \cos (3 \alpha 3)+a_{5} \cos (3 \alpha 3 \\ a_{1} \cos (5 \alpha 1)+a_{2} \cos (5 \alpha 2)+a_{3} \cos (5 \alpha 3)+a_{4} \cos (5 \alpha 3)+a_{5} \cos (5 \alpha 3 \\ a_{1} \cos (7 \alpha 1)+a_{2} \cos (7 \alpha 2)+a_{3} \cos (7 \alpha 3)+a_{4} \cos (7 \alpha 3)+a_{5} \cos (7 \alpha 3 \\ a_{1} \cos (11 \alpha 1)+a_{2} \cos (11 \alpha 2)+a_{3} \cos (11 \alpha 3)+a_{4} \cos (11 \alpha 3)+a_{5} \cos (1\end{array}\right.$

The objective function is then set to optimize it. In this paper the objective function is Total harmonics distortion (THD) which is minimized by applying PSO algorithm. The objective function is given by:

$\mathrm{F}(\mathrm{t})=\frac{\sqrt{\sum_{n=3,5,7}^{49}\left(V_{n}\right)^{2}}}{V_{1}}$

\section{Particle Swarm Optimization}

PSO was invented by Russell Eberhart and James Kennedy in 1995.This algorithm is based on social simulation model.Particle swarm optimization was developed from the concept of socially structured population in nature such as bird flocks, fish schools, and animal herds. The group of population move randomly in search space to find out the optimize solution. The best position achieved by each individual is called its experience and this experience is transferred and shared to the whole population. This experience guiding the movement towards the most likely region found so far.This algorithm keeps record upon three variables.

1. Target value or goal.

2. Global best (Gbest) value which indicates particle's current input is closest to the destination.

3.Terminate value indicates the algorithm time to stop.

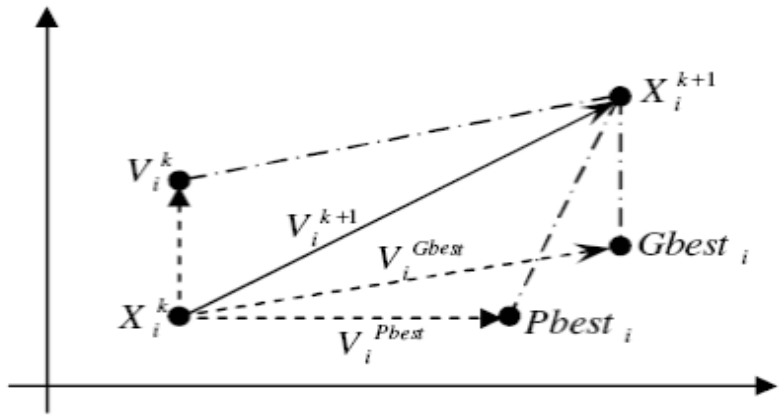

Fig.4: Optimal position search technique of a partic

$\mathrm{X}_{\mathrm{i}}^{\mathrm{k}}$ indicates present location of the particle.

$\mathrm{X}_{\mathrm{i}}^{\mathrm{k}+1}$ indicates modified location of the particle.

$\mathrm{V}_{\mathrm{i}}^{\mathrm{k}}$ indicates present velocity of the particle.

$\mathrm{V}_{\mathrm{i}}^{\mathrm{k}+1}$ indicates modified velocity of particle.

$\mathrm{V}_{\mathrm{i}}^{\text {Pbest }}$ indicates velocity depending on Pbest(personal best).

$\mathrm{V}_{\mathrm{i}}{ }^{\text {Gbest }}$ indicates velocity depending on Gbest(global best). Gbest ${ }_{i}$ indicate the best location or best velocity regulated by a set of Particle.

Pbest $\mathrm{i}$ indicate the best position or best velocity regulated by individual particle. 
In the $\mathrm{D}$-dimensional space the ith particle is characterized as $\mathrm{Xi}=$ $(\mathrm{Xi}, 1, \mathrm{Xi}, 2, \ldots, \mathrm{Xi}, \mathrm{D})$. The ith particle is noting down its best former position which is represented as: Pbesti $=($ Pbesti, 1, Pbesti, 2 ,..., Pbesti,D). GbestD is defined as the index of best particle position among all. The ith particle velocity is characterized by $\mathrm{Vi}=$ $(\mathrm{Vi}, 1, \mathrm{Vi}, 2, \ldots, \mathrm{Vi}, \mathrm{D})$. By using the following formulas the velocity and position of each individual particle is modified. It is determined by the help of present velocity and the gap from Pbesti,D to GbestD.

$\mathrm{ViD}(\mathrm{t}+1)=\mathrm{W}[\mathrm{ViD}(\mathrm{t})+\mathrm{C} 1 \mathrm{R} 1(\mathrm{PiD}-\mathrm{XiD}(\mathrm{t}))+\mathrm{C} 2 \mathrm{R} 2(\mathrm{PgD}-$ $\mathrm{XiD}(\mathrm{t}$

The position of the particle is updated by

$\mathrm{XiD}(\mathrm{t}+1)=\mathrm{XiD}(\mathrm{t})+\operatorname{Vid}(\mathrm{t}+1)$

Where

$\mathrm{XiD}(\mathrm{t})=$ particle position

$\operatorname{ViD}(t)=$ particle velocity

$\mathrm{PiD}=$ The best remembered position of individual particle.

$\mathrm{PgD}=$ The best remembered position of swarm.

$\mathrm{C} 1, \mathrm{C} 2=$ cognitive and communal parameter.

$\mathrm{R} 1, \mathrm{R} 2=$ random number between 0 and 1.

The constriction factor ' $\mathrm{W}$ ' is developed in order to assure and improve the convergence characteristic of the PSO algorithm and it is defined as:

$$
\mathrm{W}=\frac{2 k}{\left|2-C-\sqrt{C^{2}-4 C}\right|} \quad \mathrm{c}=\mathrm{c} 1+\mathrm{c} 2 ; \mathrm{c}>4
$$

\section{Pso Algorithm For 11 Level Inverter}

The main objective is THD minimization from output voltage multilevel inverter by finding out the suitable firing angels.For this the partcle swarm optimization algotithm is applied to find out that firing angles for a 11 level inverter and optimized the THD.From the swarm the trial vector that representing the $\mathrm{i}^{\text {th }}$ particle is given by $\alpha \mathrm{i}=[\alpha \mathrm{i} 1, \alpha \mathrm{i} 2, \ldots, \alpha i \mathrm{~s}] . \alpha \mathrm{i}$ are the angles for solving the harmonic minimization problem, and the Dth element of that is corresponding to the $\mathrm{D}^{\text {th }}$ switching angle of the inverter. The steps are mentioned below to solve the SHE problem with unequal dc

sources.

1) In the first step, the population size and maximum iteration number is as-

signed as $\mathrm{P}$ and itermax respectively and the iteration counter is set to iter $=1$.

2)The initial position of individual particle(the switching angle) is randomly

developed between 0 to $\pi / 2$.the velocity vector of the particle is also devel

oped randomly between $-V \max$ and $V \max$.

3)The individual particle is graded by the help of fitness function of the harmon-

ic minimization problem.

The fitness function is given as follows:

$\mathrm{F}(\mathrm{t})=\frac{\sqrt{\sum_{n=3,5,7}^{49}\left(V_{n}\right)^{2}}}{V_{1}}$

4) In this step personal best position of particles is updated. If the present position

of the $\mathrm{i}^{\text {th }}$ particle is better than its former personal best position, $\mathrm{Pi}$ is replaced with the present position $\mathrm{Xi}$, and also if the best position of the personal bests of the

particles is better than the position of the global best, Pg is replaced with the best

position of the personal bests.

5) The velocity is now updated and all the particles in the population are updated by

using the formulae (6) and (7).

6) Termination process. If iter = itermax the, the algorithm will stop; else, the itera

tion counter will be iter $=$ iter +1 and go back to step( 3 ).

\section{Matlab Program and Result}

By implementing PSO algorithm an 11 level inverter was designed.To prove this concept MATLAB program and simulation was carried out. Here 5 inverters with unequal voltage sources are connected in cascade. The voltages are $\mathrm{V} 1, \mathrm{~V} 2, \mathrm{~V} 3, \mathrm{~V} 4, \mathrm{~V} 5$.The relation of these dc voltages with nominal dc voltage is $\mathrm{V} 1=\mathrm{a} 1 \mathrm{Vdc}$, $\mathrm{V} 2=\mathrm{a} 2 \mathrm{Vdc}, \mathrm{V} 3=\mathrm{a} 3 \mathrm{Vdc}, \mathrm{V} 4=\mathrm{a} 4 \mathrm{Vdc}, \mathrm{V} 5=\mathrm{a} 5 \mathrm{Vdc}$. Here nominal $\mathrm{dc}$ voltage is taken 12 volt and V1 is also 12volt. It indicates $\mathrm{a} 1=1$.Similarly $\mathrm{a} 2=0.916, \mathrm{a} 3=0.833, \mathrm{a} 4=0.75$, a5 $=0.6$. Here the velocity vector varies from +50 to -50 volt. As the maximum output voltage is $\mathrm{V} 1+\mathrm{V} 2+\mathrm{V} 3+\mathrm{V} 4+\mathrm{V} 5=50$ volt. The best result how far is found out by using matlab programming is $\mathrm{THD}=5 \%$ in single phase 11 level inverter. The set of switching angles providing the minimum THD are:

$\alpha 1=4.890, \alpha 2=12.070, \alpha 3=23.210, \alpha 4=39.190, \alpha 5=56.590$ in de gree.

\subsection{Fft Analysis}

FFT analysis was done using matlab programming with different modulation index.The figure is shown below.

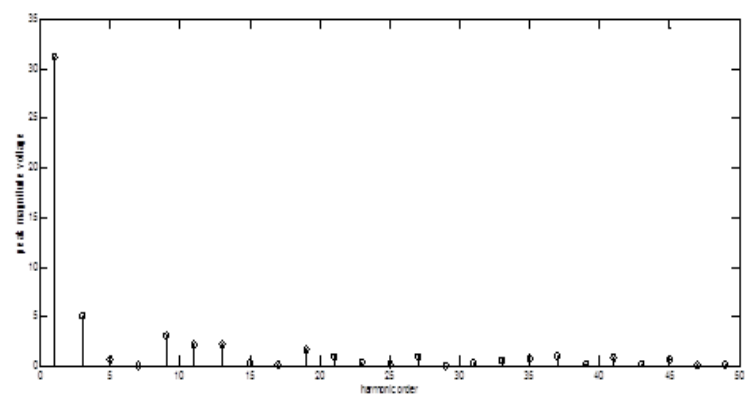

Fig.5: Peak magnitude voltage VS harmonic order with modulation index 0.66

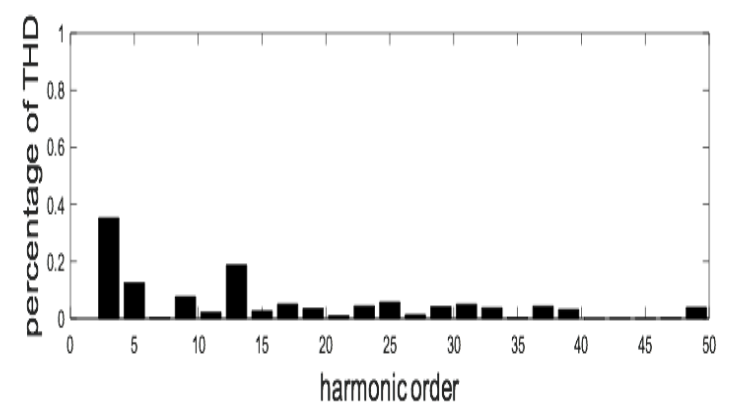

Fig.6: Harmonic order with its distortion with modulation index 0.66

The FFT was calculated up to 49th order harmonics.From fig(5) $3 \mathrm{rd}$ harmonic voltage is $5 \mathrm{~V}$ and 5 th order harmonic voltage is $0.8 \mathrm{~V}$.From fig(6) 3rd harmonic distortion is 0.37 and 5th harmonic distortion is 0.18 with modulation index 0.66 . 


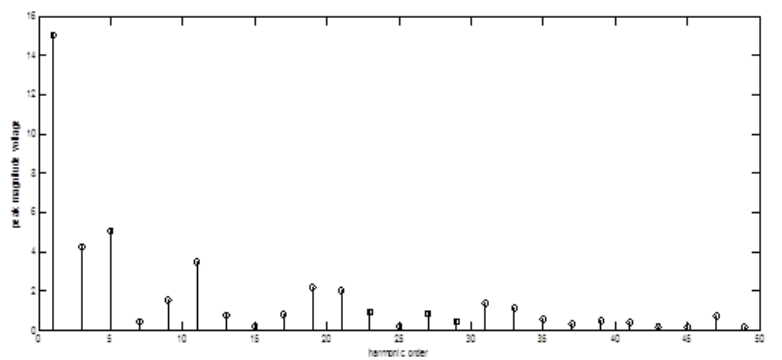

Fig.7: Peak magnitude voltage VS harmonic order with modulation index 0.7

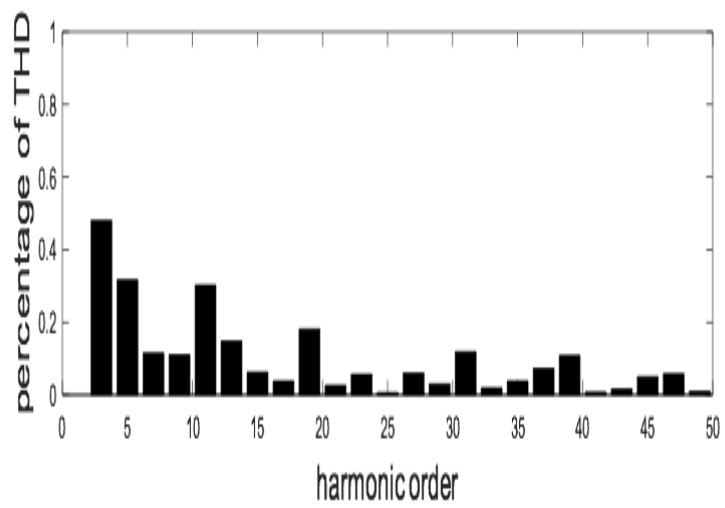

Fig.8: Harmonic order with its distortion with modulation index 0.7

From fig (7) 3rd harmonic voltage is $4.2 \mathrm{~V}$ and 5 th order harmonic voltage is $5.8 \mathrm{~V}$.From fig (8) 3rd o harmonic distortion is 0.48 and 5th harmonic distortion is 0.3 with modulation index 0.7.In this case the overall THD is found out $6.6 \%$.As compare with modulation index 0.66 , in this case 5th order harmonic peak voltage and percentage of THD is more.

To get the validation of the computational results for switching angles the matlab program was done and simulation was carried out in MATLAB/SIMULINK software for an 11-level cascaded H-bridge inverter. The nominal dc voltage is considered to be 12 $\mathrm{V}$ and the 5 different dc voltages which are used in 5 different inverters are $8,9,10,11,12$ volt. The inverter which is triggered on first is energized with $12 \mathrm{~V}$ and the inverter that is operated for small duration is supplied with $8 \mathrm{~V}$. Simulation results are presented for modulation index 0.66 .The line to line voltage waveform that found out from simulation is shown below.

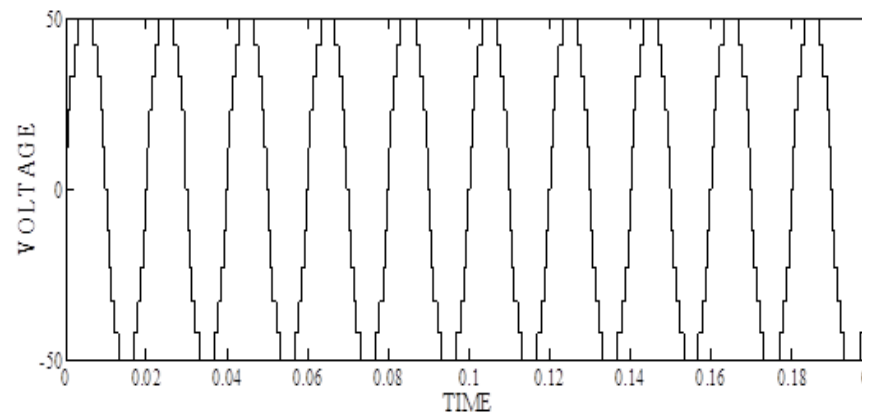

Fig.9: Line to line voltage waveform with respect to time

\section{Experimental Setup}

In fig (10) the hardware of 11 level inverter and the staircase output waveform across the load is shown.Here 5 batteries with different voltage has taken.Mosfet driver circuit is programmed with appropriate firing angle which was got from MATLAB programme.The output wave form was tested by using CRO.By the help of DSO the THD was measured
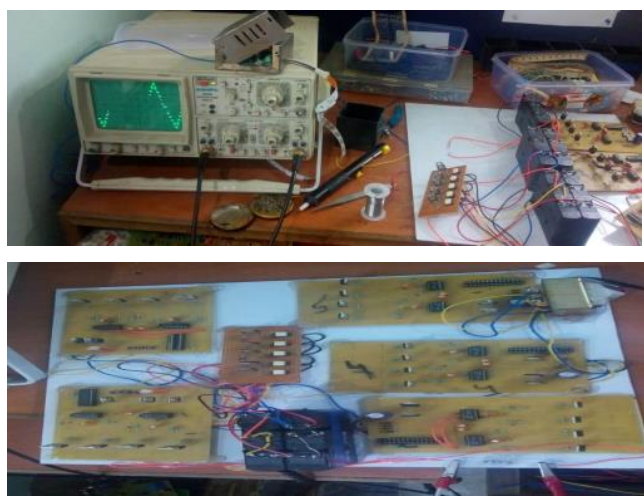

Fig.10: Experimental set up of multilevel inverter and output wave form across load

\section{Conclusion}

Different heuristic methods have been proposed to solve the SHE problem. Due to the smooth convergence criteria PSO algorithm has drawn attention of researchers towards it to get the best result in optimization. For getting the minimum value of THD by the help of cascade multilevel inverter here PSO algorithm is used and optimum switching angles for inverters were found out. With fewer derivations, less numbers of equations and less time the experiment was carried out successfully. To proof the concept a single phase 11 level inverter was design and simulate by the help of swarm optimization.

\section{References}

[1] Frank Mihalic,Miro Milanovic,Alenka Hren, Third harmonic elimination by SPWM for filter reduction in a over modulated single phase inverter,IEEEXplore,Electrical Drives and power electronics,ISSN:13393944,Date-1-12- 2017.

[2] D. G. Holmes and T. A. Lipo, Pulse Width Modulation for Power Converters, Piscataway, NJ: IEEE Press, 2003.

[3] S. Kouro, J. Rebolledo, and J. Rodriguez, Reduced switching-frequency modulation algorithm for high Power multilevel inverters, IEEE Transaction.Industrial. Electronics. vol. 54, no.5, pp. 2894-2901, Oct. 2007.

[4] .W. Fei, X. Du, and B. Wu, A generalized half-wave symmetry SHEPWM formulation for multilevel voltage inverters ,IEEE Transactions.Industrial electronics, vol. 57, no. 9, pp. 3030-3038, Sep. 2010 .

[5] Taghizadeh H. and Tarafdar Hagh M., Harmonic Elimination of Cascade Multilevel Inverters with Nonequal DC Sources Using Particle Swarm Optimization ,IEEE transactions on industrial electronics, 57(11), November 2010.

[6] J. N. Chiasson, L. M. Tolbert, K. J. McKenzie, and Z. Du, The use of power sums to solve the harmonic elimination equations for multilevel converters, EPE J., vol. 15, no. 1, pp. 19-27, Feb. 2005.

[7] L. M. Tolbert, J. N. Chiasson, K. McKenzie, and Z. Du, Elimination of harmonics in a multilevel converter with non-equal DC sources, in Proceeding. IEEE Appl. Power Electronics. Conference, Miami, FL, Feb. 9-13, 2003, pp. 589-595.

[8] Y. Liu, H. Hong, and A. Q. Huang, Real-time calculation of switching angles minimizing THD for multilevel inverters with step modulation, IEEE Transactions. Industrial Electronics, vol. 56, no. 2, pp. 285-293, Feb.2009.

[9] Y. Liu, H. Hong, and A. Q. Huang, Real-time algorithm for minimizing THD in multilevel inverters with unequal or varying voltage steps under staircase modulation, IEEE Transactions. Industrial Electronics, vol. 56, no. 6,pp. 2249-2258, Jun. 2009.

[10] Rupali Mohanty,Sthitaprajna Rath,Surya Prasad Mishra, A comparison study of harmonic elimination in cascade multilevel inverter using particle swarm optimization and Genetic Algorithm,IOSR journal of Electrical and Electronics Engineering,e-ISSN:2278-1676 Volume 5,Issue 1,PP 43-49,2013.

[11] Rupali Mohanty, Gopinath Sengupta, Sudhansu Bhusana Pati, A Comparative Study Of Harmonic Elimination of Cascade Multilevel Inverter With Equal DC Sources Using PSO And BFOA Techniques, Indian journal of science and research,ISSN: 2250-0138,PP-106-110,2017

which is $6.5 \%$.. 